\section{Why Is My House So Dirty?}

\author{
James J. Benko \\ Microspec Analytical
}

Today's newer homes are built to be energy efficient. Better insulation, better caulking, better windows restrict heat and airflow movements. Dust and contamination getting into the house has a harder time getting out. PLM examination of dust is a direct approach to assessing the magnitude of the problem and identifying the contamination responsible. Several actual cases of dust problems in the home and the role of microscopy in solving these problems are discussed.

\section{INTRODUCTION}

Many home owners today are discovering that their newer homes are showing excessive dirt. These homes are built to be energy efficient. They are better insulated. They are not as open to the outdoors as in the past (windows closed and air conditioned in the summer, recirculating kitchen fans not exhausted to the outside, self-contained chimneys on the furnace do not allow mixing with house air). As a result dirt that gets into, or is produced within the house, cannot get out easily. Better lighting, wider windows, cathedral ceilings, white walls, white cabinets, and light-colored carpets tend to show dirt more readily. Any soot produced by fireplaces, ovens, woodstoves, etc. is typically found as black stains on carpets and walls around door frames and heat registers. Static charges attract dirt/soot to plastic surfaces such as electrical outlet face plates, picture frames, clocks, clothes hampers, etc.

The home owner seeing this contamination gradually increase, despite conscientious cleaning efforts, often becomes frustrated and asks the question- "What is this black stuff and where is it coming from?" The microscopist is in a good position to answer these questions. First of all, is the contaminant really black, or it something that just appears dark? Dust can be composed of many of different things. Possibilities include carbon soot from various sources, white powders in the home (bath powder, talc), humidifier scale, soil, pollen, mold, mildew, etc. Many of these materials possess a distinctive morphology and are readily identified by a trained PLM microscopist.

House dust is generally a mixture of many different things. Soot can be one component. Other components may be hair (from occupants, pets, and pests), skin cells (humans may shed up to 400,000 cells/min. $)^{1}$, insect parts, pet dander, plas-

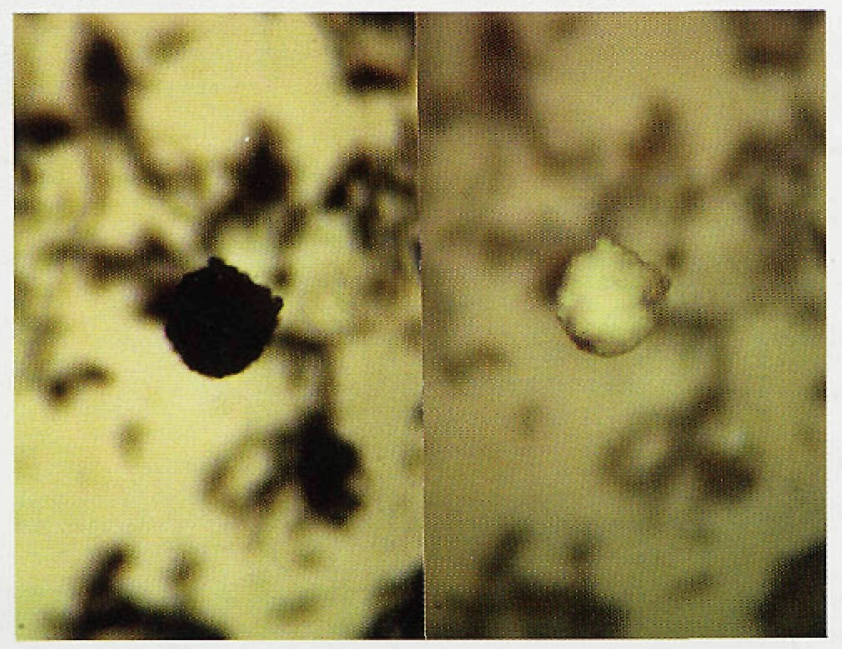

Figure 1. 160X. Left-Particle illuminated with transmitted light appears black. Right-Same particle illuminated with reflected light appears white ter, mold, sawdust, baby powder, food residues, and cleaner residues. Light microscopy is good in first identifying components of house dust and may be all that is needed. Morphology and particle size are a definitive identification step. Chemical microcrystal tests are also useful. Instrumental tests are used to further characterize the dust, if these preliminary tests do not identify the material.

At Microspec Analytical, we see several house dust problems every year. Black soot appears to be the biggest problem. Obvious soot sources are fireplaces, wood stoves, smokers, cooking stoves (food overflows in ovens), and sooty fuels used in auxiliary space heaters. Other sources may be potpourri heater pots, oil lamps, chafing dishes, and range hood exhaust fans. Other not so obvious sources are car exhaust from a connected garage, candles, and certain aerosol products used in the home. Each problem is unique and although carbon soot is a re-occurring theme, it is not the only dust problem in the home. It is important to keep an open mind for other possible dust sources.

A typical project may involve visiting the home to observe the dust/soot problem first hand. Interviewing the homeowners helps to define the scope of the problem and to get specific details. One should obtain a furnace filter with significant dust accumulation for further testing and also take dust samples from several heat vents/ cold air returns. Also it is a good idea to take samples from undisturbed areas such as tops of doorframes and joists in basements. We also take dust samples from areas outside the home (siding, top of doorframes, etc.) for examination and comparison.

Some cases can be difficult. Sometimes the home occupants are not objective. To them any black looking material is soot, but there may not be a verifiable soot problem. White, or off-white, dust can appear dark under certain lighting conditions (Figure 1). The homeowner may be convinced of perceived problems that cannot be verified by sampling. Thorough photographic home evidence and photomicrographs of collected dust samples become very important in establishing and justifying final conclusions.

Soot can easily be isolated and identified but the actual source may prove elusive. Sometimes no positive source identification is possible. Where candles are implicated or suspected of causing the soot, it may be difficult to prove that they alone are the problem, especially to the house owner.

PLM examination of the dust, however, can be supplemented with other instrumental tests to further characterize the sample. FTIR microscope analysis of dust samples is a powerful identification tool. Solvent extraction of dust/soot particles collected from different areas of the home is often worthwhile. Analysis of evaporated residues by infrared microscopy can often provide clues to sources of dirt/soot/dust. Cooking grease, vegetable oils, some

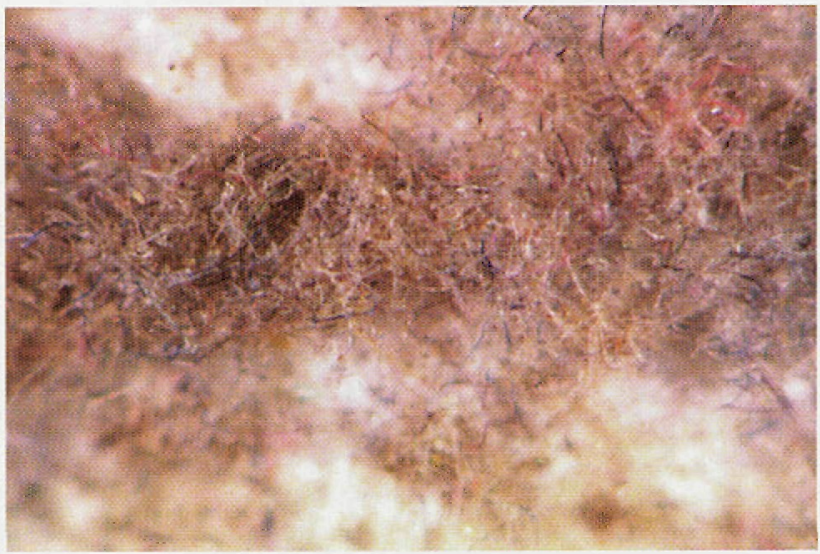

Figure 2. Dust Sample showing very little carbon soot

Continued on page 18 


\section{FAST!
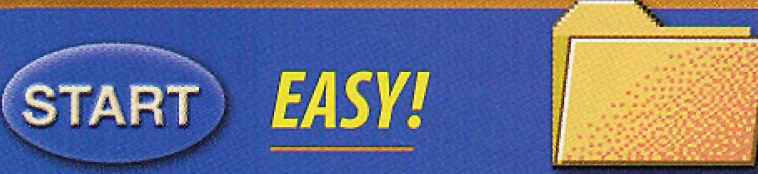

\section{Featuring}

\section{Spectral Imaging}

Acquire spectra, x-ray maps and linescans -

all in one data set!

- Spectrum at every point

- Data re-analysis to create spectra, $x$-ray maps and linescans

- Real-time display of data

- Easy-to-use interface with single-point frame resizing

- Resume acquisition when more data is needed

- Dead-time correction of all data

- Dedicated hardware for high throughput

- Spectra from spots, lines, rectangles, or user-defined shapes

- Data compression routines

- Automatic ROIs

- Formatted print output

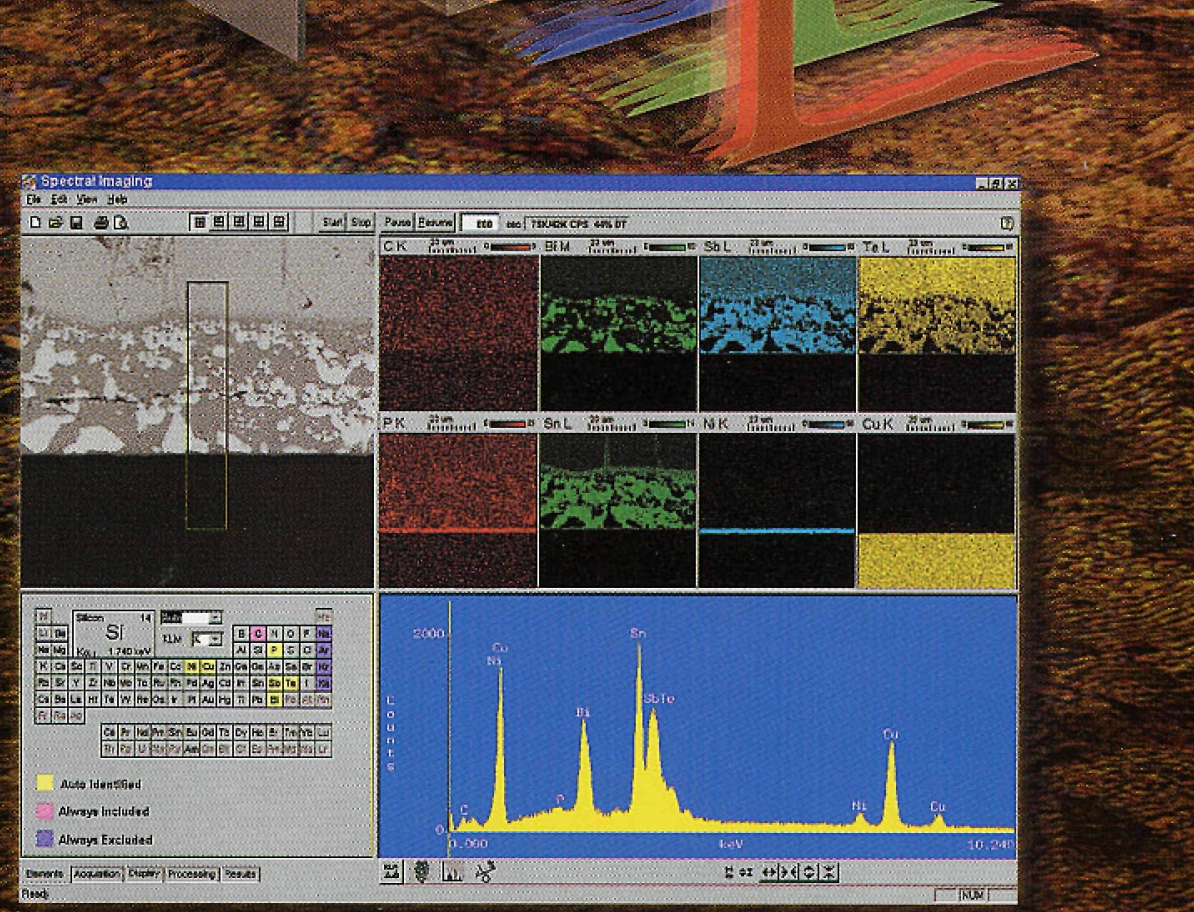

United States: (608) 831-6511

The Netherlands: (31) 356998888

Japan: (81) 442466190
Germany: (49) 725197910

United Kingdom: (44) 1869327711 Worldwide Web: http://www.noran.com
NoRAN

INSTRUMENTS

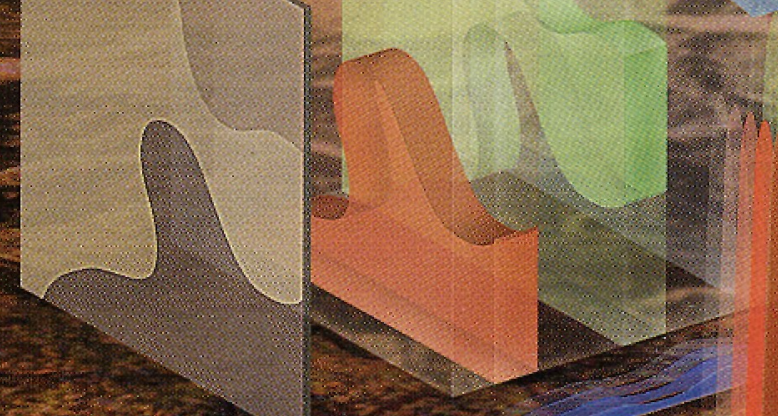


Why Is My House So Dirty?

\section{Continued from page 16}

candle wax formulations, and certain semi-volatiles may provide definitive spectra. Residues from cleaning/polishing products can also give unique infrared spectra (oils, silicones, etc). For example, FTIR showed silicone oil to be a component of a chloroform extract of TV screen dust in one home with excellent agreement between grease on a kitchen stove exhaust fan with a chloroform extract of lunch meat (bologna).

Checking evaporated solvent extracts from dusts taken from cold air returns and furnace filters is often worthwhile. It is my belief that soot is formed from residues of certain aerosol products used in the home. Residues from these products build-up imperceptibly over time and soot may form months after use of the causative agent. One way that this may occur is that the residues can be carried into the ductwork of cold air returns and can accumulate on the furnace heat exchanger during spring, summer, and early fall--periods when the furnace is not being used to heat the home. Then when the furnace is used on a daily basis in late fall or early winter, these residues may become charred on the outer surface of the heat exchanger and produce very fine soot that can travel throughout the home. Often, furnace inspections are more concerned with checking soot production from the fuel source and, short of tearing the entire furnace apart to check the outside surface of the heat exchanger, any soot produced from residues on the outer surface of the exchanger is hard to verify. Nevertheless, this is a scenario that should be considered. It was the most likely explanation of a soot problem in one of the cases discussed.

\section{CASE HISTORIES}

Several cases of soot/dust problems investigated at Microspec Analytical over the last few years are described below. They illustrate the wide variety of problems concerning the homeowner and show the utility of the light microscope in characterizing various dusts found throughout the home.

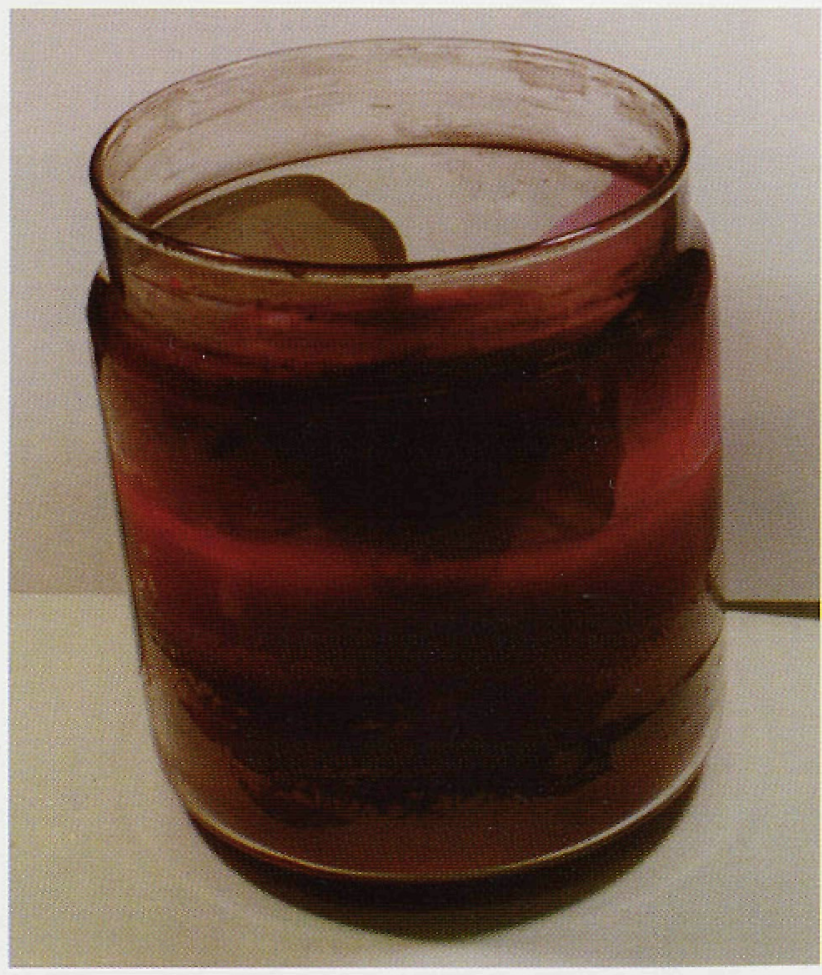

Figure 3. Candle with soot deposit on glass jar.

\section{Case 1 - Perceived Problems}

The home owners were convinced they had a soot problem in their new home. Residues from the furnace filter they supplied did not have any appreciable soot. Microscopical examination showed only lint composed mostly of numerous natural and synthetic fibers of various colors. Dust samples were taken from registers and ductwork. They were similar to dust found on the furnace filter. Again no significant amounts of black soot could be found. Photomicrographs of dust from the furnace filter and ductwork were used to document findings that carbon soot was not the problem and that lint was the main component of the dust (Figure 2).

\section{Case 2- Candles}

A furnace filter from the home was submitted for analysis. It contained a significant amount of black carbon soot and some lint. Interviews with the homemaker showed that three or four large candles were lit during several weeks before and after Christmas. One of the candles was submitted for analysis. The candle was in a glass jar that had observable soot near the opening. See Figure 3. The label on the jar stated that the wick should be cut to no more than $1 / 4$ inch or that soot production could be a problem. During long periods of burning, it would be difficult to keep the wick that short. There was obviously a possibility for significant amounts of soot to be produced by these candles over an extended period of time. Research has shown that some types of candles can produce up to 100 times the soot of others ${ }^{2}$. A candle placed in an air draft can increase soot production by a factor of 50 .

\section{Case 3-Humidifier Dust}

Dust particles collected from various areas of ductwork and the furnace filter were dark, but not totally black, as soot would be. Microchemical tests showed the presence of both carbonate and calcium in this dust. Adding a drop of dilute sulfuric acid to a small particle of dust in a drop of deionized water on a microscope slide provided a two for one micro-chemical test. Strong fizzing occurred. This indicated carbonates. Much of the material dissolved. After the fizzing subsided, the prep was examined again under the microscope. Needle-like crystals of gypsum were observed, indicating the presence of calcium (Figure 4).

The dust sample was characterized as mainly hard water deposits. These deposits were eventually traced to a furnace mounted humidifier in need of cleaning.

\section{Case 4-Bath Powder}

White dust was found throughout the home, but mainly upstairs, concentrated mainly in the bathroom. Both bathroom ex-

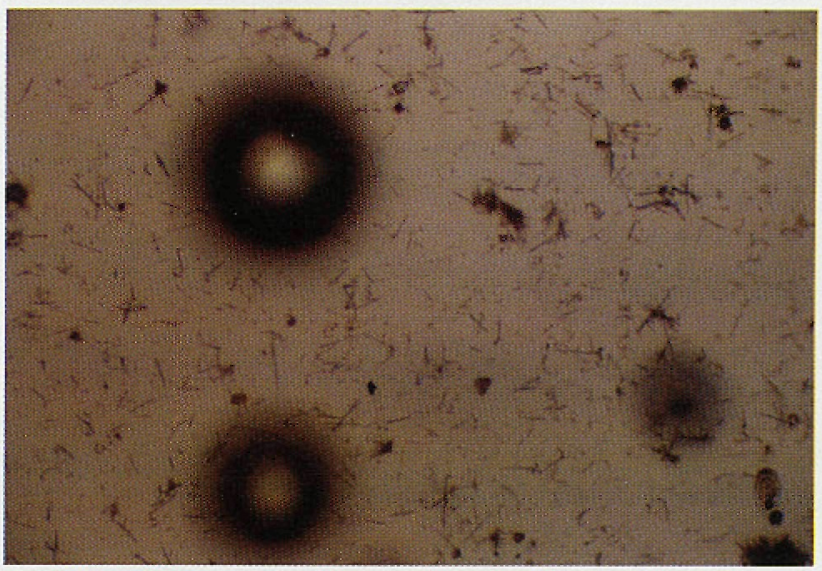

Figure 4. Water hardness scale in dilute sulfuric acid showing bubbles of carbon dioxide from carbonates and thin needles of gypsum indicating the presence of calcium

Continued on page 20 
Why Is My House So Dirty?

\section{Continued from page 18}

haust fans from the upstairs and downstairs contained similar white dust. FTIR analysis of the dust showed it to contain significant amounts of talc. Interviews with the homeowners confirmed that bath (talcum) powder was used frequently after showers and baths.

\section{Case 5 - Apartment above Garage}

Soot was noticed on and around electrical outlets mainly on outside walls of this apartment. The furnace was inspected and found to be in good working order. Other apartments in the same building did not have a similar problem. This apartment was the only one located above a four-stall garage in the building. It was observed that cars were often started to warm them up during cold spells before being driven out of the garage. Soot from auto exhaust appears to be responsible for the observed problem.

\section{Case 6 - Hairspray}

A new home (less than one-year old) was observed with a soot problem. Soot was found on plastic surfaces, around flowerpot bases, and on rugs around doorframes, etc., throughout the home. Black dust could also be seen on the cold air return register in the living room. The home was finished in early spring. The soot problem became noticeable in December/ January about nine months later. Evaporated chloroform extraction of the black dust from both the furnace filter and cold air return produced a resinous product and an infrared scan of this material matched very well those of hair spray residue. The two occupants of the home (widow and teenage daughter) both were users of hair spray. It was theorized that hair spray was being drawn into the cold air return and deposited on the furnace heat exchanger during spring, summer, and fall. When the furnace was used in the winter, these residues became charred and produced a fine soot. Furnace inspections showed that the furnace was operating normally.

\section{Case 7 - Mildew}

We were asked to characterize a black residue on an outside air conditioner cover. It had the appearance of an industrial soot deposit, but closer microscopical examination of sample scrapings showed it to be fungi (Figure 5). A quick microchemical test using a drop of household bleach on the scrapings changed the color from black to white. Carbon black soot would have remained essentially unchanged (Figure 6). A morphological exam of the fungi showed it to be most likely Cladosporidium sphaerospermum ${ }^{3}$ which is a very common fungus living on damp paper, paintwork, and textiles.

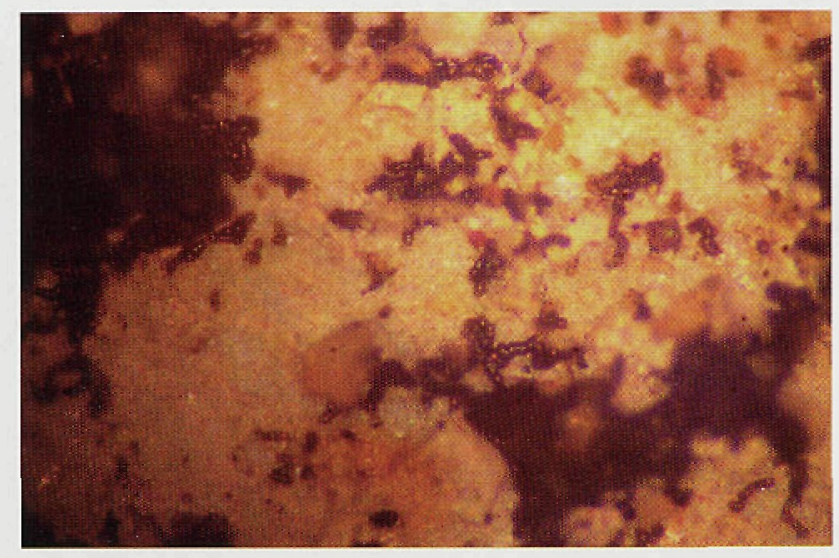

Figure 5. Fungi growing on painted surface of metal substrate.

\section{Case 8 - Carpet Beetles}

A new home was observed with a small, but noticeable deposition of soot around ceiling corners, mainly in the living room and adjoining rooms near a fireplace. The problem was traced to the fireplace having a poorly fitting glass door assembly that allowed a small amount of smoke to backflow into the room. In the course of examining duct work and other areas of the home, however, excessive sawdust, carpet fibers, and dirt were found in some of the ductwork near register openings. One sample provided several larvae of carpet beetles that were obviously feeding on this debris (Figure 7). This hidden problem was potentially more serious to the homeowner than the original soot problem.

\section{CONCLUSION}

Dust problems in the home are the result of many diverse causes. Carbon soot may also be the result of several different scenarios. The first step in solving any of these problems should be a thorough PLM examination of the dust. This will enable characterization and identification of many of the causative agents. Sufficient samples should be collected for other microchemical and instrumental tests that may be required. The problems should be adequately documented with photos and photomicrographs.

1. Grand Rapids Press, Grab a damp cloth to start dusting off those mites. There's more crud in dust than you want to know, April 5, 1998, by Laura Christman of Scripps Howard News Service.

2. Air Conditioning, Heating, and Refrigeration News, Candles Blamed for Indoor Air Soot, January 9, 1998, pp.1-2.

3. Microfungi On Miscellaneous Substrates, An Identification Handbook, by Martin Ellis and J. Pamela Ellis, Timber Press, Portland, OR, 1988, p. 168

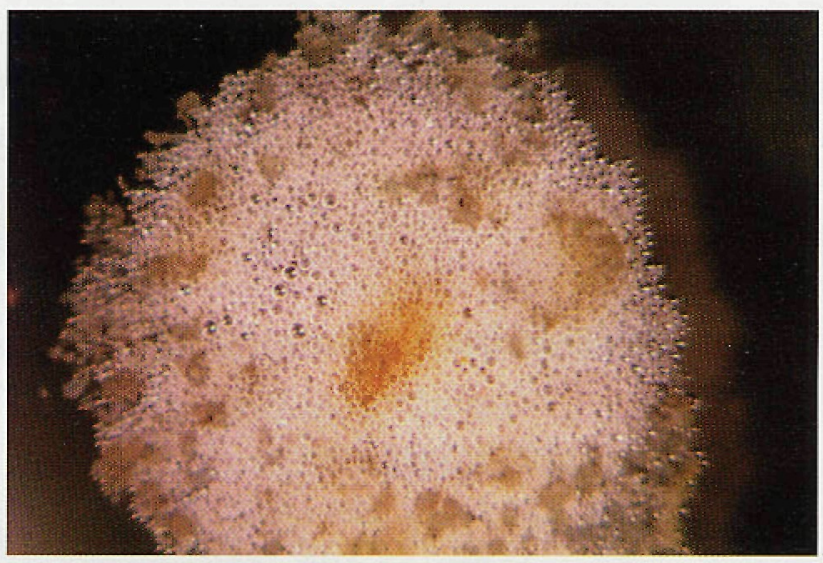

Figure 6. Bleach destroys the black coloration of mildew.

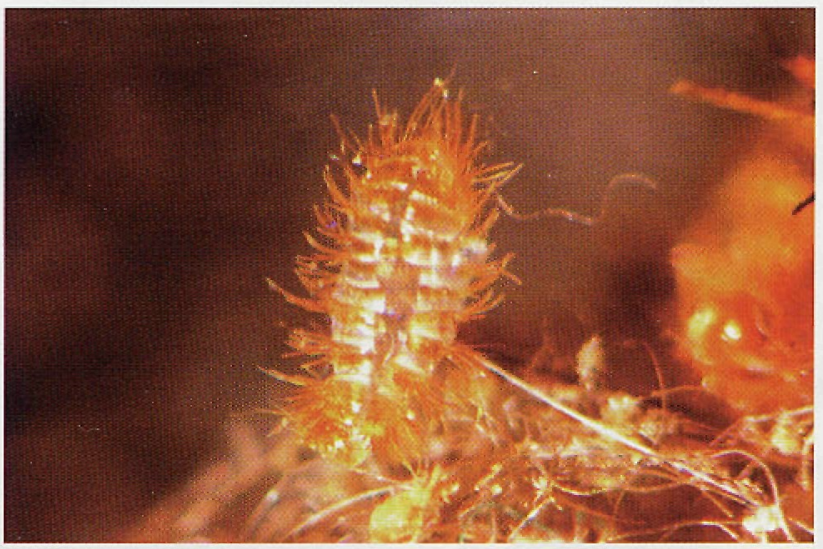

Figure 7. Carpet beetle larval stage,

Reprinted from The Microscope, Vol. 48, Third Quarter, 2000, The McCrone Research institute. 